\title{
Research on the Core Competence and Training System of Computer Speciality for Big Data Processing in Colleges and Universities of Finance and Economics
}

\author{
Fumin Ma \\ College of Information Engineering \\ Nanjing University of Finance and Economics \\ Nanjing, China 210023
}

\begin{abstract}
In big data era, the computer professionals should be equipped with the ability of big data processing and analysis. And multi-disciplinary collaborative innovation and interdisciplinary cross-learning ability is becoming more and more important. According to the market demands of big data professionals and the characteristics of finance and economics universities, the status of big data specialty at home and abroad is analyzed firstly. And then, the core competence and knowledge structure of computer specialty oriented ecommerce big data processing in finance and economics universities are refined. It has built up the theory and practice teaching system as well as quality development and guarantee system in accord with the specialty core competence. And it highlights the specialty characteristic. It also meets the needs of market and economic development.
\end{abstract}

Keywords-big data; computer speciality; core competence; training system

\section{INTRODUCTION}

Now, the big data technology has changed the operation modes of the Internet, business, finance, medical industry and other industries as well as people's lifestyles. The effective management and utilization of big data has injected new impetus for the socio-economic development. The application and analysis capabilities of big data will become the core competitiveness of all walks of life. However, it has brought opportunities to the computer industry in the era of big data. At the same time, it has also brought huge challenges to the cultivation of computer professionals [1] [2]. Combined with the development needs of the big data era and the discipline orientation of universities, it can improve the core competence of computer specialty. And it is urgent to adjust the training system of computer professionals.

As the universities of economics and finance, it is of great significance to cultivate the cross-disciplinary talents with statistical knowledge, computer technology, and economic management and so on. It is of great significance

Supported by the Education Research Foundation of Nanjing University of Finance and Economics (JGY1746). to improve the school-running characteristics and the schoolrunning level of computer specialty in colleges and universities of economics and finance. Colleges and universities of economics and finance have prominent features and advantages in economic management and ecommerce applications. It can integrate the existing professional characteristics and the construction achievements of academic resources in colleges and universities of economics and finance. It can adjust the training structure of original computer professionals. Also, it can reform the training system. It should condense the core competence of computer specialty for the big data processing in colleges and universities of economics and finance. While emphasizing the ability of students to manage and analyze big data, it will highlight the applications in Internet finance and e-commerce. And it will undoubtedly promote the cultivation of the multiplex application technological talents.

In this paper, it has analyzed the current situation of market demands of big data talents. And it also has analyzed the construction and the curriculum development of big data specialty. This paper has condensed the core competence of computer specialty for the big data processing in colleges and universities of economics and finance. And it has constructed the curriculum group, practice teaching system, quality expansion system and quality guarantee system which are suitable for the cultivation of the core professional competence. Combined with the actual situation of our school, it has formed the core competence and training system of computer specialty for big data processing in colleges and universities of economics and finance.

\section{THE CORE COMPETENCE OF COMPUTER SPECIALTY FOR THE BIG DATA PROCESSING IN COLLEGES AND UNIVERSITIES OF ECONOMICS AND FINANCE}

\section{A. The Demand Situation of the Cultivation of Big Data Talents}

According to the survey of McKinsey Global Institute, America will face a shortage of about 1.5 million big data experts by 2018. IDC forecasts that it will lack 181000 deep 
data analysts in the US by 2018. According to the first report on big data talent in China in 2016, it will lack as high as 1.5 million big data talents in the next three to five years. The lack of related talents will have impact on the development of big data market [3], [4]. According to the analysis of demands of related jobs of big data in the major recruitment sites all over the world, the demands of big data talents can be summarized as data planners, data engineers, data architects, data analysts and data application engineer. On the job responsibilities, the related positions of big data need versatile talents. And these versatile talents have knowledge on data, computer, business analysis and other aspects.

\section{B. The Construction of Related Specialty of Big Data at Home and Abroad}

The University of California, Berkeley, North Carolina State University, Columbia University, the Oxford University in British, London Imperial College have set up the data analysis earlier abroad. The cultivation of data science talents in colleges and universities mainly focuses on graduate students. Some colleges set up the data science in the business school. It is called the master of business data analysis. And some colleges set up the data science in the school of engineering. It is mainly on the analysis of computer science data. Also, some colleges set the data science in the school of management. Absolutely, many colleges have set up the research center of big data. For example, it has built financial big data lab in the Oxford. From the perspective of personnel training, most colleges and universities require students to have mathematical and computer knowledge. And these colleges also set up economics, statistics, marketing and other courses. And they pay attention to the cooperation with the related industries.

The cultivation of big data talents in China mostly focuses on cultivation of the master and doctoral students. Tsinghua University, Fudan University, Beihang University and other colleges and universities have set up research center of big data. Many colleges and universities have set up big data technology and application under the computer science and technology. In the cultivation of undergraduates, 35 colleges and universities have been approved to set up data science and big data technology by 2017. Peking University, University of International Business and Economics, and Central South University were firstly approved to set up data science and big data technology in 2016. And it is four-year undergraduate specialty. In the talent training program, they stressed that graduates should have basic knowledge of information science, management science and data science and basic skills. The graduates should have big data engineering system integration capabilities, application software design and development capabilities and basic ability and quality of big data science research.

\section{Analysis of Core Competence and Knowledge Structure of Computer Specialty for Big Data Processing in Colleges and Universities of Economics and Finance}

The real value of big data technology is to analyze and use the large-scale data with the massive, heterogeneous and unsound characteristics in the application. And then, $t$ can excavate its potential relevance. Therefore, big data technology should be the integration of many disciplines. It includes computer, mathematics, statistics, management, marketing, etc. [5]. From the view of development trend, it lacks the cross-type talents in the big data. And the crosstype talents must master the knowledge of data and computer and business analysis capabilities.

On the basis of the demands of above-mentioned talents, the determination of the core competence of computer specialty for big data processing in colleges and universities of economics and finance will be considered from the aspects of training target orientation, service orientation and school characteristics. Colleges and universities of economics and finance often have distinctive feature in the financial, economic and business management. Therefore, both the big data analysis of Internet finance and ecommerce data analysis can service for the market well. And it can highlight the characteristics of the colleges and universities. It should consider their uniqueness, internality and extension of the core competence. Combined with the advantages and characteristics of our school in the current $e$ commerce applications, it can condense the characteristics of computer specialty for e-commerce big data processing with the support of the national e-commerce information processing and international joint research center. It can show the core competence, the ability of computer programming, algorithm analysis and application ability, big data structure and management ability, big data analysis and application ability, e-commerce software development and implementation ability, and e-commerce data acquisition and analysis ability. From the view of the structure of professional knowledge, the students in computer specialty with the characteristics of e-commerce big data processing and analysis should master the basic knowledge of computer science and technology, basic theory and methods. On the basis of mastering the basic operation and research and development skills of computer science and technology, it has strong ability of big data management. For example, it has acquisition, storage, processing and analysis capabilities of Internet and e-commerce data. It can master the ability of big data management and architecture. At the same time, they must be familiar with e-commerce management, application and analysis and other aspects of knowledge. "Fig. 1" shows the core competence and knowledge structure of computer specialty for e-commerce big data processing and analysis. 


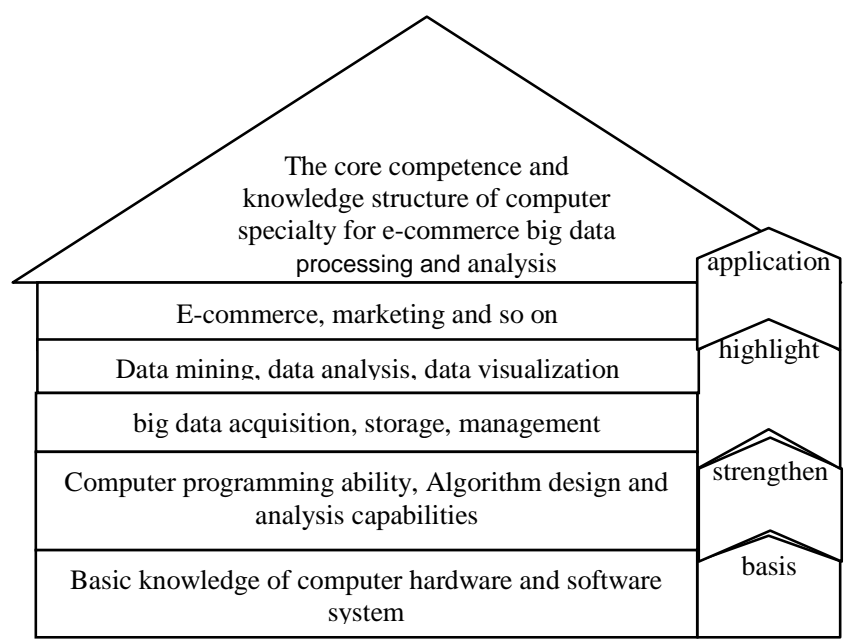

Fig. 1. The core competence and knowledge structure of computer specialty for e-commerce big data processing and analysis.

\section{THE TRAINING SYSTEM OF COMPUTER SPECIALTY FOR BIG DATA PROCESSING IN COLLEGES AND UNIVERSITIES OF ECONOMICS AND FINANCE}

The traditional computer specialty aims to cultivate engineering and technical personnel who can engage in the development, application and maintenance of computer hardware and software systems. However, computer professionals with the ability of big data processing as the center should solve the problem of acquisition, processing, storage and analysis of structure and unstructured data on the basis of certain knowledge of mathematics, computer and application [6]. In view of the large amount of knowledge demands for big data management and application, they may be in different disciplines. The undergraduates in computer application and technology are impossible to master all the relevant knowledge [7], [8]. In accordance with the professional characteristics, personnel training system can follow the ideas of "introduction - foundation - professionpractice-expansion". It has adjusted the objective of personnel cultivation for big data processing in computer specialty in 2017 . The computer specialty adopts the training principles of "to have solid foundation, pay attention to cross training, to highlight the application". It requires the students to have all-round development of morality, intelligence physique and aesthetic. And the students should have good scientific spirit and engineering literacy, and master solid knowledge of computer hardware and software. Also, they should have the abilities of computer application development and computer information processing, big data analysis and other aspects of professional knowledge and abilities. The students should be familiar with e-commerce and Internet data processing and analysis. In the end, they can be versatile talents.

\section{A. The Theory and Practice Teaching System should be Adapted to the Core Competence}

The theory and practice teaching system should follow the principle of interdisciplinary coordination and crossing. And it should be constructed according to the idea of "introduction-foundation-profession-practiceexpansion".

1) The construction of theoretical teaching system: Computer specialty is wide-scope specialty on both hardware and software. And it has new requirements of big data processing and analysis for the computer professionals in the era of big data. The construction of the theoretical teaching system of computer specialty for e-commerce data processing should connect with the core competence professional ability. And then, it can construct the theoretical training system of "basic ability + professional ability + development ability".

The corresponding curriculum group of the basic competency includes general curriculum group and basic curriculum group of mathematics. And the general curriculum group includes the basic principles of Marxism, Mao Zedong Thought and other ideological and moral cultivation courses, college English, college sports, professional introduction and so on. The basic curriculum group of mathematics includes higher mathematics, engineering linear algebra, probability theory, discrete mathematics and so on. The corresponding curriculum group of professional ability training includes the curriculum group of programming, the curriculum group of computer, the curriculum group of big data processing and analysis. And the curriculum group of programming includes programming languages for structure, object-oriented and network, and data analysis. The curriculum group of computer includes 8 courses of computer specialty designated by the Ministry of Education. The curriculum group of big data processing and analysis includes database technology, parallel and distributed computing, big data technology, data mining, data visualization and other courses. The corresponding curriculum group of the expansion capacity training is on the big data application. It includes e-commerce, recommendation system, business intelligence, mobile application development, marketing, complex network and market analysis courses. "Fig. 2" shows the theoretical teaching system that is adapted to professional competence. 


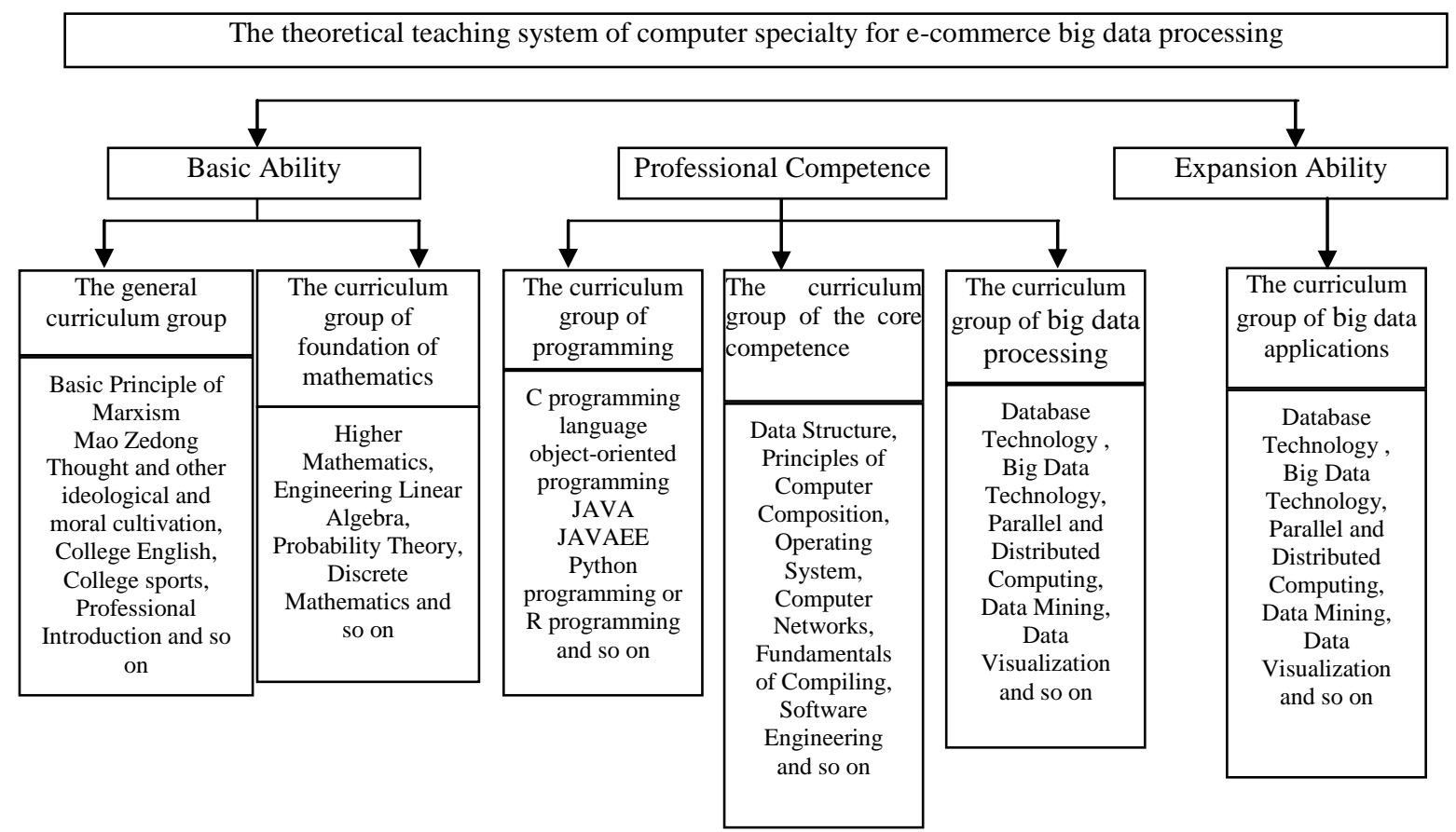

Fig. 2. The theoretical teaching system of computer specialty for e-commerce big data processing.

2) The construction of practical teaching system: The practical teaching system focuses on cultivating students' ability to solve practical problems in big data application. With the characteristics of the Internet and e-commerce applications, it should construct multi-dimensional and multi-dimensional practice training system of in-class experiments, curriculum design, school platform practice, off-campus practice, graduation design and business practice. In-class experiments focus on the theoretical teaching system. The curriculum design includes comprehensive design and professional design. The offcampus practice activities include subject competition and summer internships and other activities. In the school platform, the students should take participation in the program. In the professional training process, it should pay attention to the case of the students' life. For example, it can take Alipay, Taobao, crowd funding and Meituan as the examples to stimulate students' interest.

\section{B. The Development and Quality Assurance System should be Adapted to the Core Competence}

The core competence isn't just technical ability. And the good overall quality which is adapted to the core competence is one of the important components. In the training system of professional personnel, it should connect the learning in the first classroom with the practice in the second classroom effectively. It should enhance the professional skills of students. At the same time, it must enhance the quality of students. Combined with the orientation of talent cultivation of e-commerce data processing, it should develop and arrange rich and colorful competition in different semesters according to market demands. For example, it hosts the competition of curriculum design between freshman and sophomore. And it also host blue bridge cup software contest, cloud computing contest, college students computer design competition, challenge cup contest between sophomore and junior. In addition, the implementation of innovative training programs for college students also provides a platform for quality expansion. In the construction of quality assurance system, it will build the campus practice platform with the support of e-commerce key laboratory in the personnel training. Also, it will build off-campus joint practice base with cooperative enterprises. At the same time, it should give these competitions the right credit identification, distribution and selection and other protection mechanisms. In the talent training program, it can increase the curriculum of innovation and entrepreneurship. And then, it will encourage and protect students in all kinds of professional quality and expansion practice.

\section{CONCLUSION}

Big data technology has close relationship with computer specialty. It has also brought an opportunity for computer specialty in colleges and universities of economics and finance. The cultivation of computer professionals for big data processing in colleges and universities of economics and finance should pay attention to the students' basic knowledge of computer. At the same time, it should highlight big data architecture, management and analysis and its application in business and financial management. In this paper, it has explored the core competence and knowledge structure of computer specialty for e-commerce big data processing. And it constructs the curriculum group and practice teaching system which is compatible with the core competence. It designs the reasonable quality expansion and quality guarantee system. And then, it provides a set of progressive talent training system for big data processing of computer specialty in colleges and universities of economics and finance. 


\section{REFERENCES}

[1] Grillenberger, Andreas, and R. Romeike. Big Data-Challenges for Computer Science Education. Informatics in Schools. Teaching and Learning Perspectives. Springer International Publishing, 2014: 2940.

[2] Hazzan, Orit, and C. A. Shaffer. "Big Data in Computer Science Education Research". ACM Technical Symposium on Computer Science Education ACM, 2015:591-592.

[3] Doke, Deedee. "BIG DATA JOBS", 2013.

[4] Gholson, Lloyd. "Big data challenge". Quality Progress, 2014.

[5] He, Zhong Lin, X. H. Xiao, and Y. H. He. "Research on Information Technology with the Consideration of Computer Professional Education in Big Data Era. ” Advanced Materials Research vol. 1014, no. 1014, 2014: 429-433

[6] Zhang, Xiaofang, F. Wang, and X. Huang. "Research on Big Data Curriculum System and Specialty Construct at Home and Abroad." International Conference on Education, Management and Social Science, 2014.

[7] Zhu, Yangqing, and J. Zuo. "Probe into setting up big data processing specialty in Chinese universities". International Conference on Computer Science \& Education IEEE, 2014: 566-569.

[8] Liu, Yujun, W. F. Wang, M. Cai, and K. Chen. "The Courses System Design for Computer Profession Based on Application Ability". Journal of Higher Education Research, 2013, vol. 36, no. 2: 97-100. 